\title{
Knowledge Mapping of Energy Systems Research in 1970-2020
}

\author{
A.V. Mikheev ${ }^{*}$ \\ Melentiev Energy Systems Institute of Siberian Branch of Russian Academy of Sciences, Irkutsk, Russia
}

\begin{abstract}
This study presents a brief bibliometric overview of large scientific literature data related to issues of energy systems research from 1970 to 2020 in the Scopus database. The six periods depending on different publication activity rates were analyzed to observe the evolution of research topics of energy systems. VOSviewer software was used to construct scientific knowledge maps and to discover valuable main topics for each period. Proposed visualization of the energy knowledge domain can be considered as a necessary step for a holistic understanding of complex development pathways towards the future sustainable energy systems.
\end{abstract}

Index Terms-energy systems, power systems, knowledge mapping, big data, research trends, bibliometric analysis, scientometric analysis, visual analysis, VOSviewer.

\section{INTRODUCTION}

Energy systems are the most complex technical systems people invented. The world's energy systems implement integrated and continuously working technologies for the production, transmission, distribution, and consumption of energy. In the 21 st century, we should expect drastic changes in the energy sector. This new energy transition is related not only to the intensive development of energy technologies, in particular, renewable energy sources, a qualitative shift in the scale of adoption of intelligent information and communication technologies and means

\footnotetext{
* Corresponding author.

E-mail: avmiheev@gmail.com
}

http://dx.doi.org/10.38028/esr.2020.03.0007

Received October 1, 2020. Reviewed October 23, 2020. Revised November 7, 2020. Accepted November 20, 2020.

This is an open-access article under a Creative Commons Attribution-NonCommercial 4.0 International License.

C) 2020 ESI SB RAS and authors. All rights reserved. of control of energy facilities and systems, but also to a fundamental change in the paradigm of development of energy systems as client-oriented infrastructure systems that provide reliable and efficient services to industries and the community [1].

The transition to future energy systems requires a comprehensive understanding of the respective knowledge development. However, this is a complicated task because a lot of various interrelated topics, subject categories, technologies, and actors are involved in consideration of the energy systems knowledge domain. Multidisciplinary studies that include and integrate different fields are necessary to identify and understand feedbacks and interactions between energy systems components and hold the promise for advancing holistic system-level knowledge of energy systems.

There are a lot of publications implementing scientometric or bibliometric approaches to review various aspects of the energy sector. For example, the evolution of research on multi-energy systems such as smart grids and microgrids is considered in [2]. The work [3] assesses the global scientific research on low-carbon electricity both quantitatively and qualitatively over a large number of publications from the Science Citation Index Expanded (SCI-Expanded). Comprehensive review and scientometric analysis of prosumer flexibility as an important property of modern power systems is a good example of a holistic viewpoint providing the hotspot knowledge map of the topic [4]. Nevertheless, there is no scientometric assessment of energy research in the context of systems semantics.

This study addresses a scientometric review of the scientific literature related to the historical development of energy systems research. Opposite to the aforementioned studies this article mainly focuses on:

- summarizing the past and recent existing international research efforts in the field of energy systems;

- understanding main research directions and their transformation over the past 50 years based on the recovered topic clusters;

- knowledge mapping with keywords' co-occurrence network. 


\section{DATA AND TOOLS}

The methodology of the study is a scientometric analysis joint with supporting visualization to provide an in-depth understanding of the research structure and trending topics in the field of energy systems. The scientometric analysis is a well-established technique to construct a knowledge map of the specific area over a large massive dataset of scientific literature. An example of a scientometric review of global research on sustainability and sustainable development can be found in [5].

General workflow of scientometric analysis includes several sequential steps:

1. Publications data retrieval related to a specific problem or knowledge area.

2. Data cleaning manually or automatically to remove irrelevant publications.

3. Scientometric quantitative analysis applying various metrics like betweenness centrality to construct different co-occurrence networks. The network examples are coauthorship network, co-word network, co-terms network, co-citations network, and others. Further clustering analysis over the constructed networks is also an important part of the scientometric approach.

4. Knowledge domain visualization and in-depth analysis to obtain status-quo of research, discover emerging trends, hidden interrelations, and other valuable outputs.

In this study, the Scopus database was selected as the most comprehensive and easy-to-use international data source. A search in the database was carried out using the base phrases "energy system*" and "power system*". Symbol "*" is inserted instead of the end of the words to satisfy a fuzzy search of both plural and single word forms. The publications with the language "English" and document type as "Article" and "Review" from reviewed and trusted journals were selected. We consider the long period 1970-2020 when the different rates of publications growth are observed.

The final query text inserted in the bar of "Advanced search" of the Scopus search engine is presented below.

TITLE-ABS-KEY ( "energy system*" OR "power system*" ) AND ( PUBYEAR > 1969) AND PUBYEAR < 2021 AND ( LIMIT-TO ( DOCTYPE , "ar") OR LIMIT-TO ( DOCTYPE, "re")) AND ( EXCLUDE ( SUBJAREA, "BIOC") OR EXCLUDE (SUBJAREA, "MEDI") OR EXCLUDE ( SUBJAREA , "ARTS") OR EXCLUDE (SUBJAREA, "HEAL") OR EXCLUDE (SUBJAREA , "PSYC") OR EXCLUDE (SUBJAREA, "NEUR") OR EXCLUDE (SUBJAREA , "PHAR") OR EXCLUDE (SUBJAREA, "NURS") OR EXCLUDE (SUBJAREA "IMMU") OR EXCLUDE ( SUBJAREA, "VETE" ) OR EXCLUDE ( SUBJAREA, "DENT") OR EXCLUDE ( SUBJAREA, "Undefined")) AND ( LIMIT-TO ( LANGUAGE , "English" ) )

To avoid including irrelevant documents, for example from medical science, the search results were filtered to remove the subject areas far from "Energy" like "Medicine", "Nursery", "Computer Science", "Arts and Humanities", etc. On the other hand, since "energy" is a multidisciplinary topic, such subject categories as "Engineering", "Chemistry", "Environmental Science", "Social Science", "Material Science", etc. remain under consideration.

The query search on September 25, 2020, gives 111260 documents including 106124 research articles and 5136 reviews. Fig. 1 presents the documents' growth statistics by years. Fig. 2 shows the distribution by countries, and by most productive sources like "IEEE Transactions on Power Systems", "International Journal of Electrical Power and

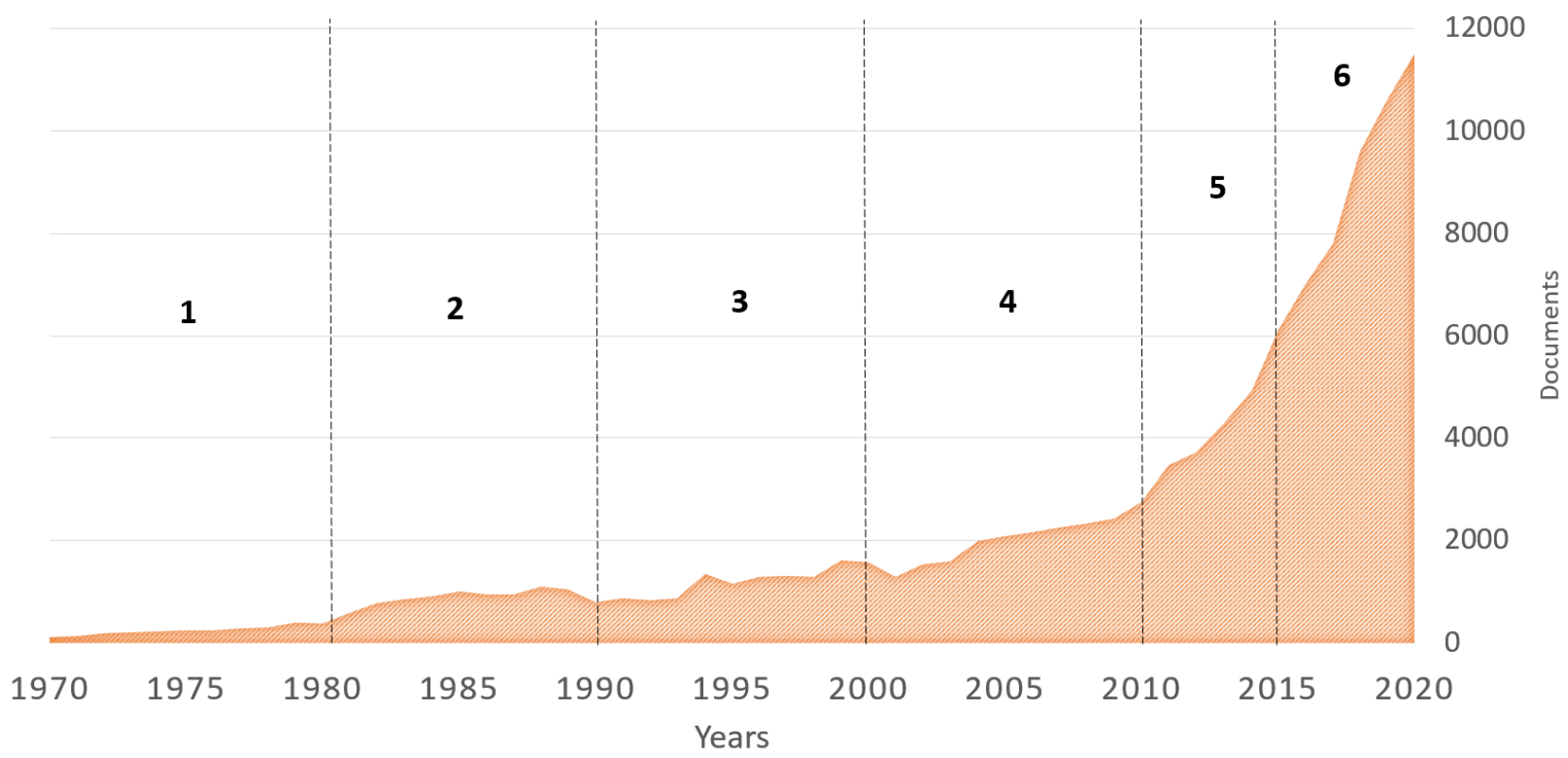

Fig. 1. Published documents growth on the field of energy systems research in the Scopus database within 1970-2020 divided into six periods. 


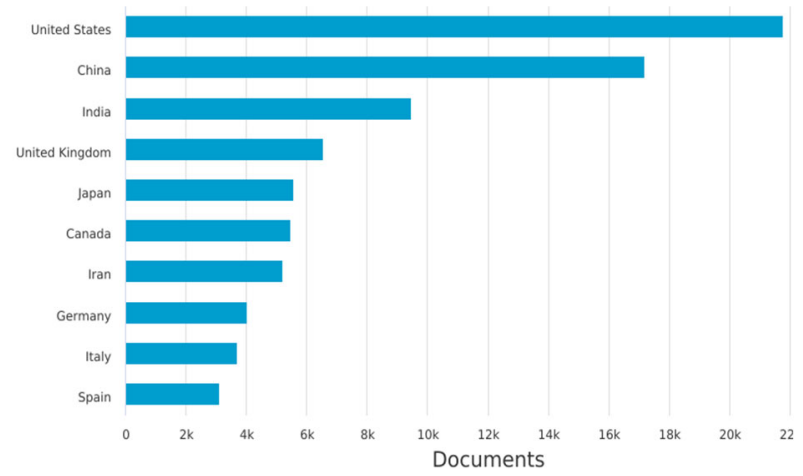

a)

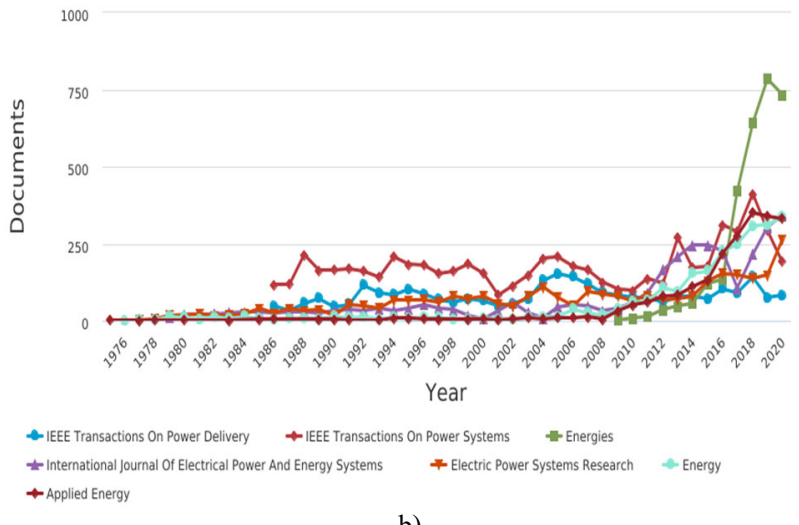

b)

Fig. 2. The number of documents on energy systems research in the Scopus database during 1970-2020 (a) country distribution, (b) most productive journals with more than 2000 documents over the entire period. The figures are received with the standard Scopus analyzer tool.

Energy Systems", "Energies, Electric Power Systems Research", "IEEE Transactions on Power Delivery", "Energy" and "Applied Energy".

To track topic changes in the knowledge domain, it is necessary to divide the entire period under consideration into characteristic time intervals. Analyzing the publication activity growth in Fig 1 we can roughly divide 50 years' interval into decades. Due to expansive publication growth, the last decade should be subdivided into two 5 years' periods in such a way as presented in Table 1 . The research history of energy systems in the past 50 years can be divided into four stages: the early period 1970s with low publication activity, the foundation period (1980-2000) with light publication growth, mature stage (2001-2010), and big data era after 2010, when explosive publication growth is observed.

To investigate key topics and their corresponding interrelations the study uses a scientometric technique, namely, co-term analysis. We employ keywords cooccurrence analysis, which is one of the basic capabilities of VOSviewer open software developed by N.J. Van Eck and L. Waltman [6] from Leiden University for scientometric analysis. VOSViewer software is widely used by researchers as a powerful analytical tool in scientometrics [7].

There are many applications of VOSviewer in the energy field, for example, to assess global research and trends in renewable energy [8, 9], in bioenergy and biomass utilization $[10,11]$. VOSviewer software is used to obtain results of co-word and cluster analysis of keywords of the papers published in the journal Renewable Energy to track 5 major clusters during 20 years' timeline 1990-2010 [12].

The perfect investigation of worldwide scientific production can be found in [13], where hot research topics of renewable energy technologies such as solar, wind, geothermal, hydro, and biomass are considered along temporal dimension for 1992-2011.

The article [14] describes a bibliometric overview of the several periods of academic research on the multidisciplinary field as knowledge management.

Advanced features are available in VOSviewer such as co-authorship, keyword co-occurrence, bibliographic linkage, and a co-citation network to represent bibliometric

Table 1. Statistics of data used for network visualization by periods.

\begin{tabular}{|c|c|c|c|c|c|c|}
\hline$\#$ & Years & Documents & Period & $\begin{array}{c}\text { Term } \\
\text { (keywords) }\end{array}$ & $\begin{array}{c}\text { Terms (keywords) } \\
\text { with occurrences }>5\end{array}$ & $\begin{array}{c}\text { Links } \\
\text { between } \\
\text { keywords }\end{array}$ \\
\hline 1 & $1970-1979$ & 2246 & $\begin{array}{c}\text { Early-stage. } \\
\text { Low publication activity }\end{array}$ & 2749 & 180 & 922 \\
\hline 2 & $1980-1989$ & 8445 & \multirow{2}{*}{$\begin{array}{l}\text { Foundation stage. } \\
\text { Small publications growth }\end{array}$} & 20490 & 1026 & 14415 \\
\hline 3 & $1990-1999$ & 11313 & & 34262 & 2216 & $34262^{*}$ \\
\hline 4 & $2000-2010$ & 19201 & $\begin{array}{l}\text { Mature period. } \\
\text { Sustainable publication } \\
\text { growth }\end{array}$ & 65703 & 5780 & $117359^{*}$ \\
\hline 5 & $2010-2015$ & 25233 & \multirow{2}{*}{$\begin{array}{l}\text { Big Data Era. } \\
\text { Explosive publications } \\
\text { growth }\end{array}$} & 92143 & 11746 & $153382^{*}$ \\
\hline 6 & $2016-2020$ & 46491 & & 134236 & 18360 & $205000^{*}$ \\
\hline
\end{tabular}

\footnotetext{
* Total number of links between 1000 "hottest" keywords.
} 
relationships between authors and between document terms. The main algorithms built-in into VOSviewer include a unified approach to mapping and bibliometric network clustering. VOSviewer software pays special attention to displaying large science maps in an easy-tointerpret way.

Besides, VOSviewer allows the use of a thesaurus file, which allows the user to clean the irrelevant data or unify the synonymic terms. In our study, the general terms like "article", "review", “journal", "study", geographical names, and so on were excluded from the total keywords list. The various forms of the term related to keywords with the same meanings were merged into a single term to resolve the issues caused by synonyms, singular/plural, hyphenated or unhyphenated descriptors, etc.

\section{MAPPING AND VISUAL ANALYSIS OF ENERGY SYSTEMS RESEARCH}

All keywords were extracted from the bibliographic dataset of collected articles and reviews. Keywords provided by authors of the paper and occurred more than 5 times were enrolled for the final analysis. For each keyword, the total strength of the co-occurrence links with other keywords was calculated.

Figures 3-8 presents the keyword network maps generated separately for the periods from Table 1 . In the maps, the sizes of the label font and the sizes of the circles are depending on the number of documents associated with each keyword. The maps display the most prominent 1000 terms to avoid overlap and unappropriated mixing. The term "electric power system" is hidden from all maps as the basic search term which is not informative and of too much weight in comparison with other keywords. The term "renewable energy" is hidden from the maps of periods 2010-2020 (see Figs. 7-8) so as not to conceal the underlying knowledge structures of renewable energy sources.

After that, the clustering analysis was applied to evaluate the main topic clusters. Color of labels and circles are used to distinguish the different clusters. All maps on the figures were constructed using VOSviewer software [6].

The map of co-occurrence keywords for the 1970s period (see Fig. 3) shows us several recognizable clusters related to most considered issues such as "system stability", "electric power transmission", "solar energy" and "mathematical modeling" and "oil hydraulic".

The second map reflecting energy systems research of the 1980s (see Fig. 4) is much denser than the previous. All main topics of the 1970s remain, but it's observed the new semantically closest terms are grown. For example, "transient stability" is one of the forms of "system stability". The terms "computer programming" and "computer simulation" correspond to "mathematical modeling" in the cluster of research approaches. The cluster of renewable energy sources "solar energy" and "wind energy" is identified more clearly on the right side of the keyword cloud, but as shown in Fig. 4 the all clustered themes are intersected and quite mixed.

One of the "hottest" keywords that appeared in the 1990s is "optimization". Researchers focus on optimal economic management and power flow dispatch control using nonlinear programming, stochastic programming, genetic algorithms, and other approaches to attain a high system efficiency of electric power generation, transmission, distribution in electric power systems.

The topic map of the 1990s on Fig. 5 outlines four main clusters related to different domains of knowledge:

(A) research methodology and tools (blue and violet colors) in the top part of the keyword network;

(B) electric power systems control issues as the yellow cluster on the left side of the map;

(C) terms of renewable energy sources as the green cluster on the right side;

(D) the intermediate red cluster of the keywords describing electric power equipment properties.

As seen further these four clusters are still paid to the attention of researchers now.

The knowledge map of the 2000s keeps the semantic core of general research methodology based on common "mathematical models", "computer simulation" and "optimization" terms as shown in Fig. 6. Additionally, the "artificial neural network" approach is a newcomer, which is used to solve problems such as fault detection on transmission lines and distribution, fast power harmonic identification, the prediction of electric loads and wind power generation, etc. The renewable energy green cluster includes a new area addressed to "energy utilization/efficiency" and "energy policy" topics challenged by carbon dioxide emission and climate change.

The trends of the first half of the 2010s illustrate a significant expansion of the renewable energy field as shown in Fig. 7. One of the central themes is "wind energy" linked with "photovoltaic system", "energy storage" (or batteries), "fuel cells". Such semantic interrelation leads later to the conception of "hybrid energy systems" appearing on the next map of 2016-2020. Of course, the renewable energy concepts have strong linkages to the conventional issues: system stability, electric power transmission and generation, computer simulation, optimization, stochastic system, and others.

Fig. 8 presents a state-of-arts or research frontier summarizing all recent main hot topics. "Optimization", "stochastic system", "uncertainty analysis", "electric power system control", "electric power transmission", "electric load flow", "power system stability", "power quality", "smart grid" as a newcomer, and wind/solar energy sources, energy storage with the respective components are a set of most popular keywords. 


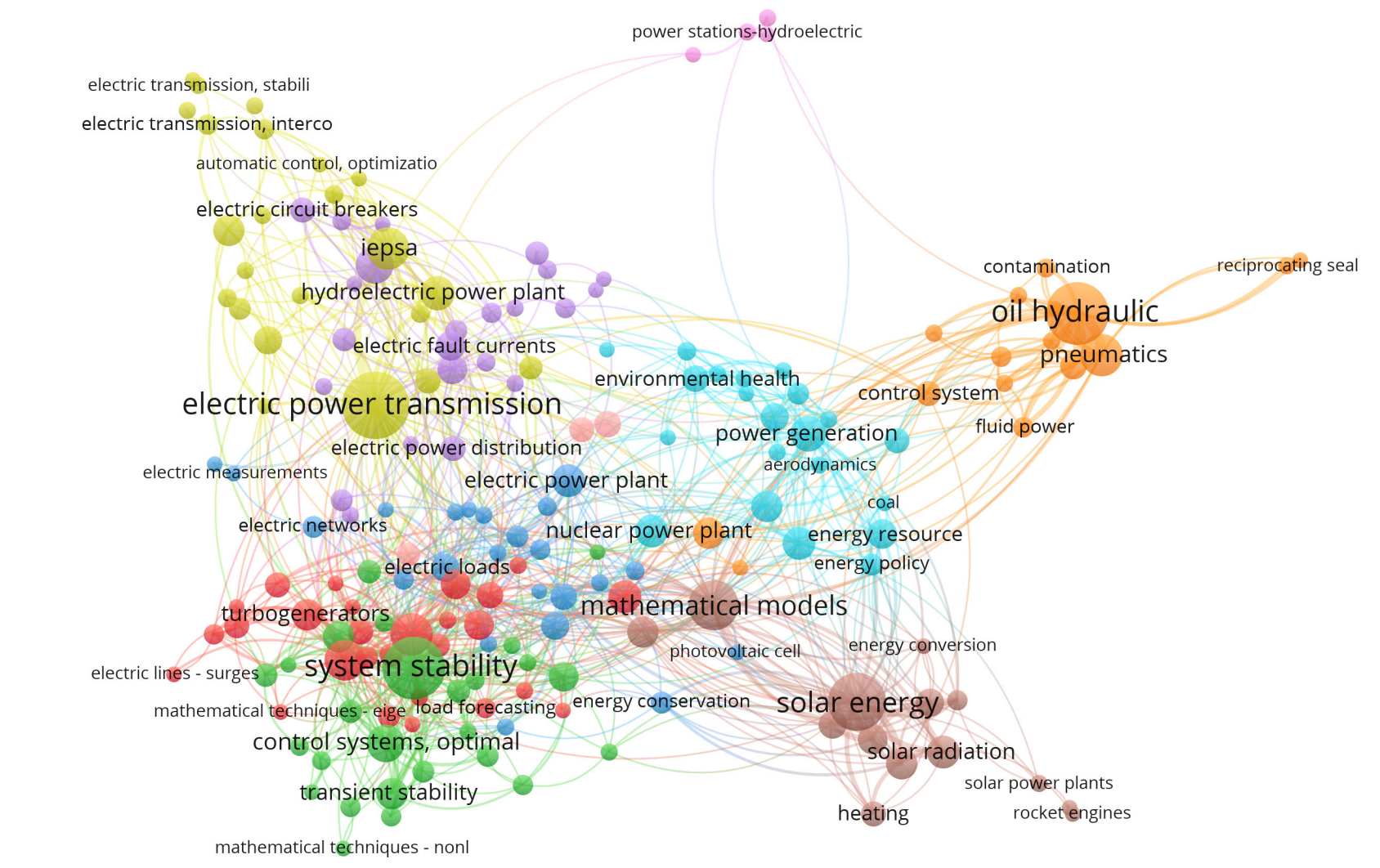

Fig. 3. Knowledge mapping of energy systems research for the 1970s.

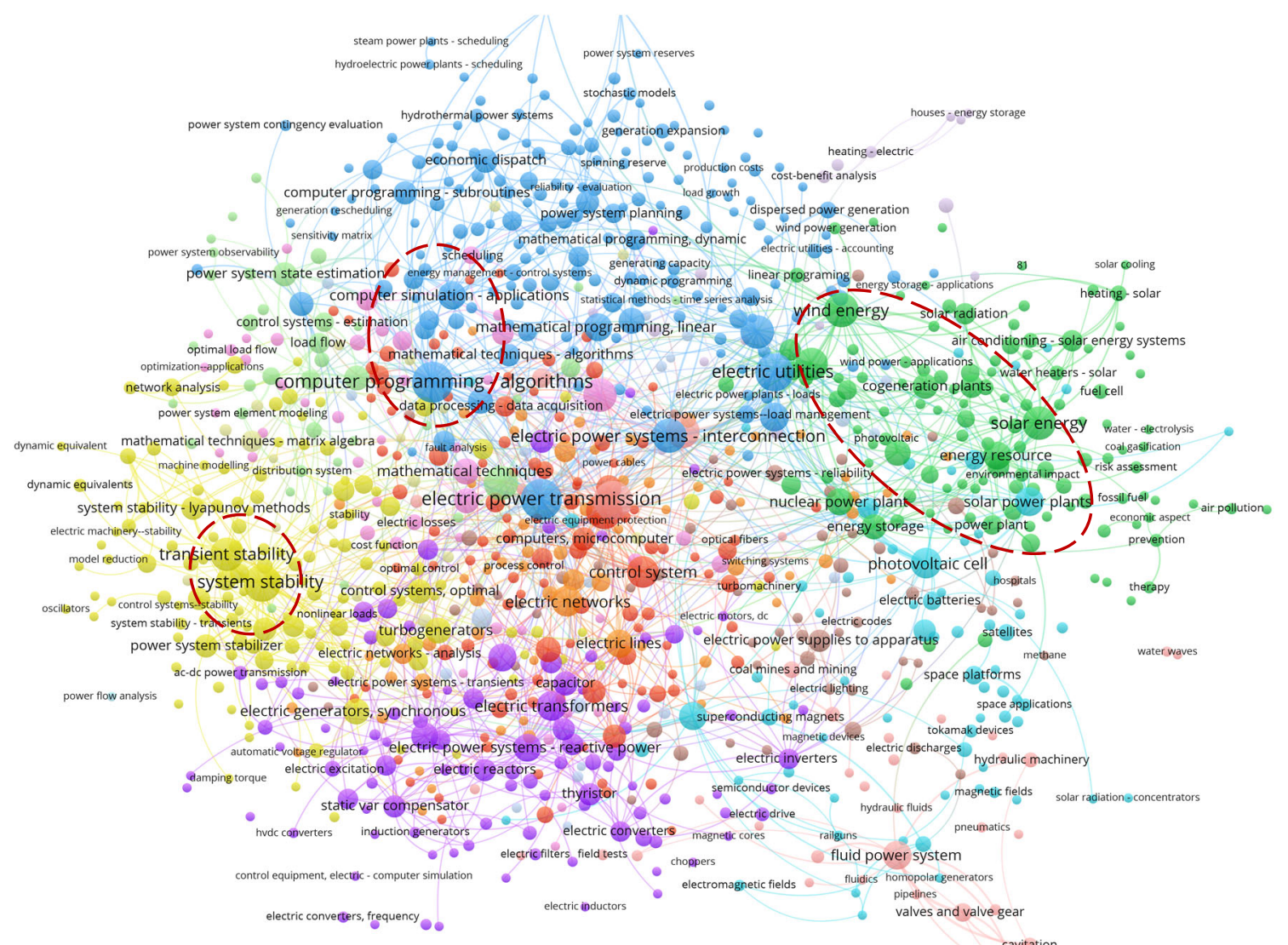

cavitation

Fig. 4. Knowledge mapping of energy systems research for the 1980 s. 


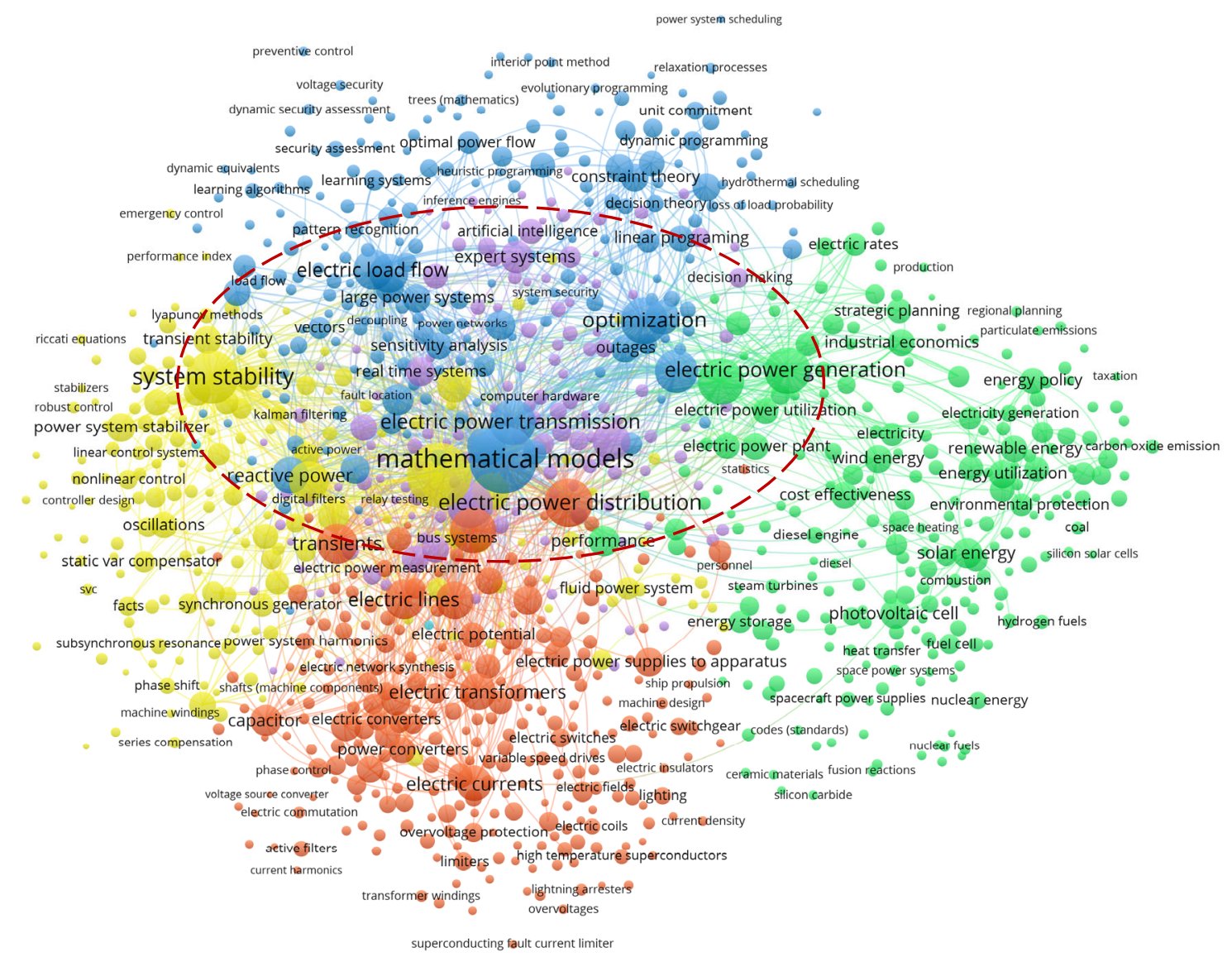

Fig. 5. Knowledge mapping of energy systems research for the 1990s.

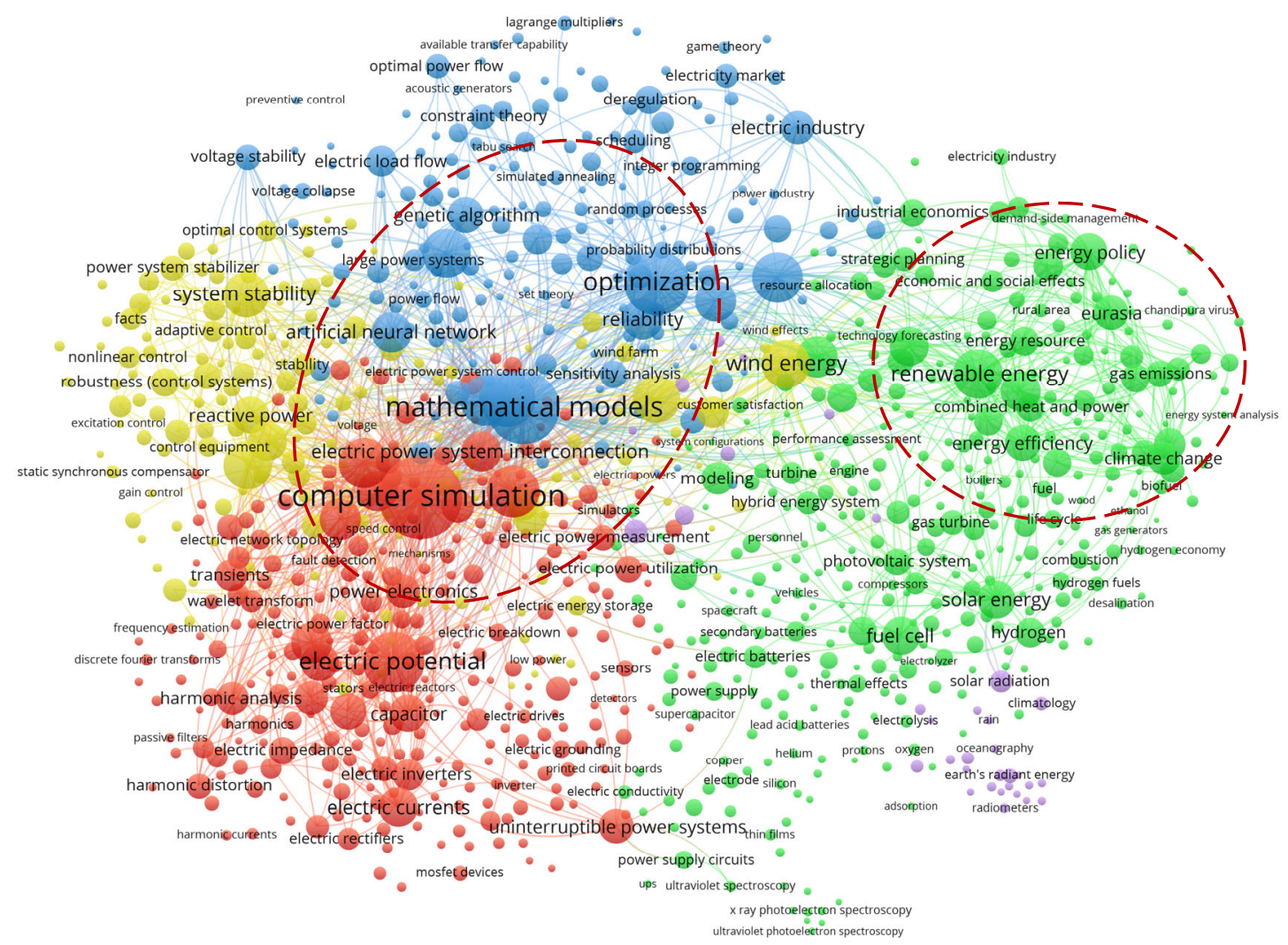

Fig. 6. Knowledge mapping of energy systems research for the 2000s. 


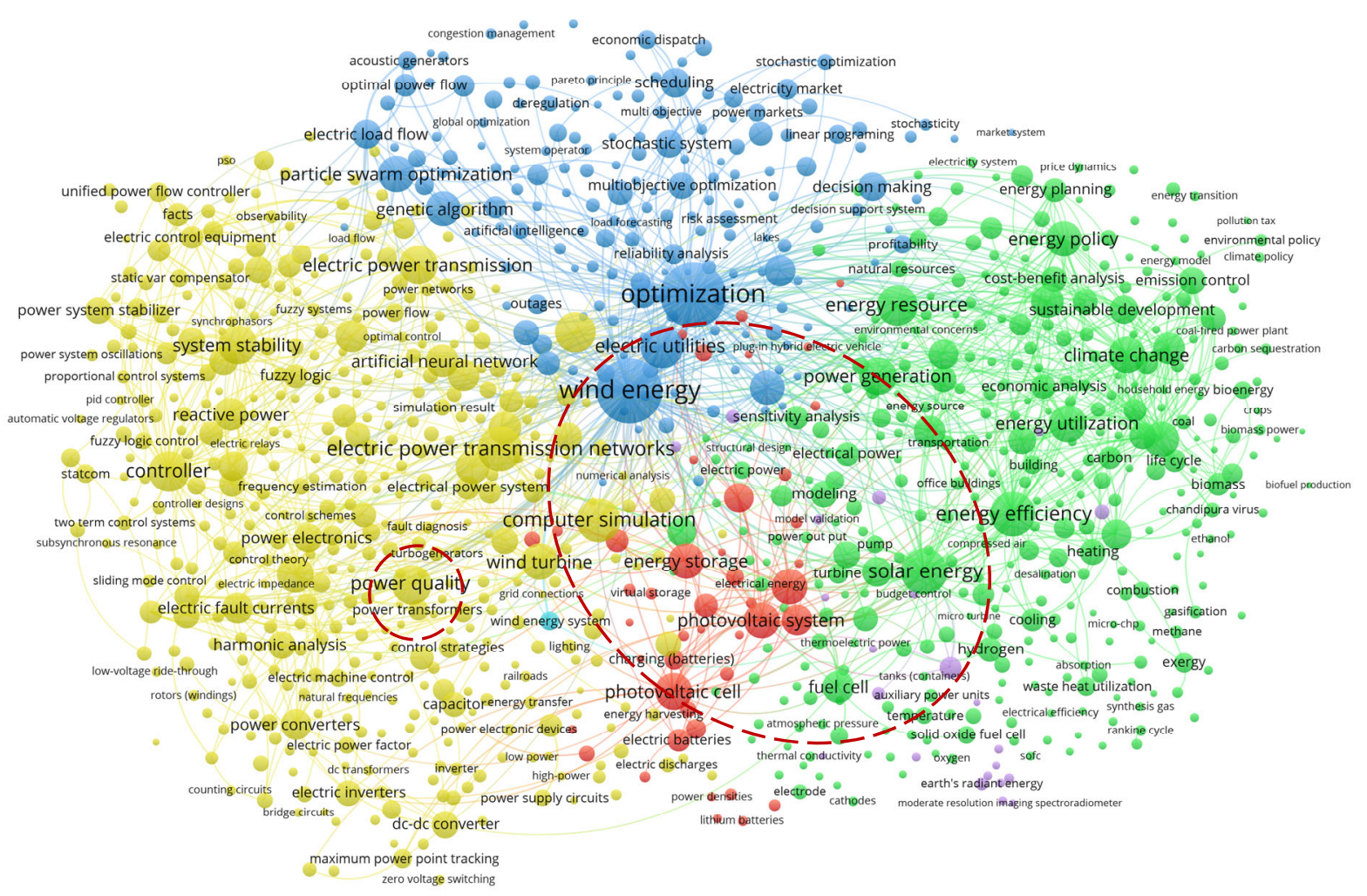

Fig. 7. Knowledge mapping of energy systems research for 2010-2015.

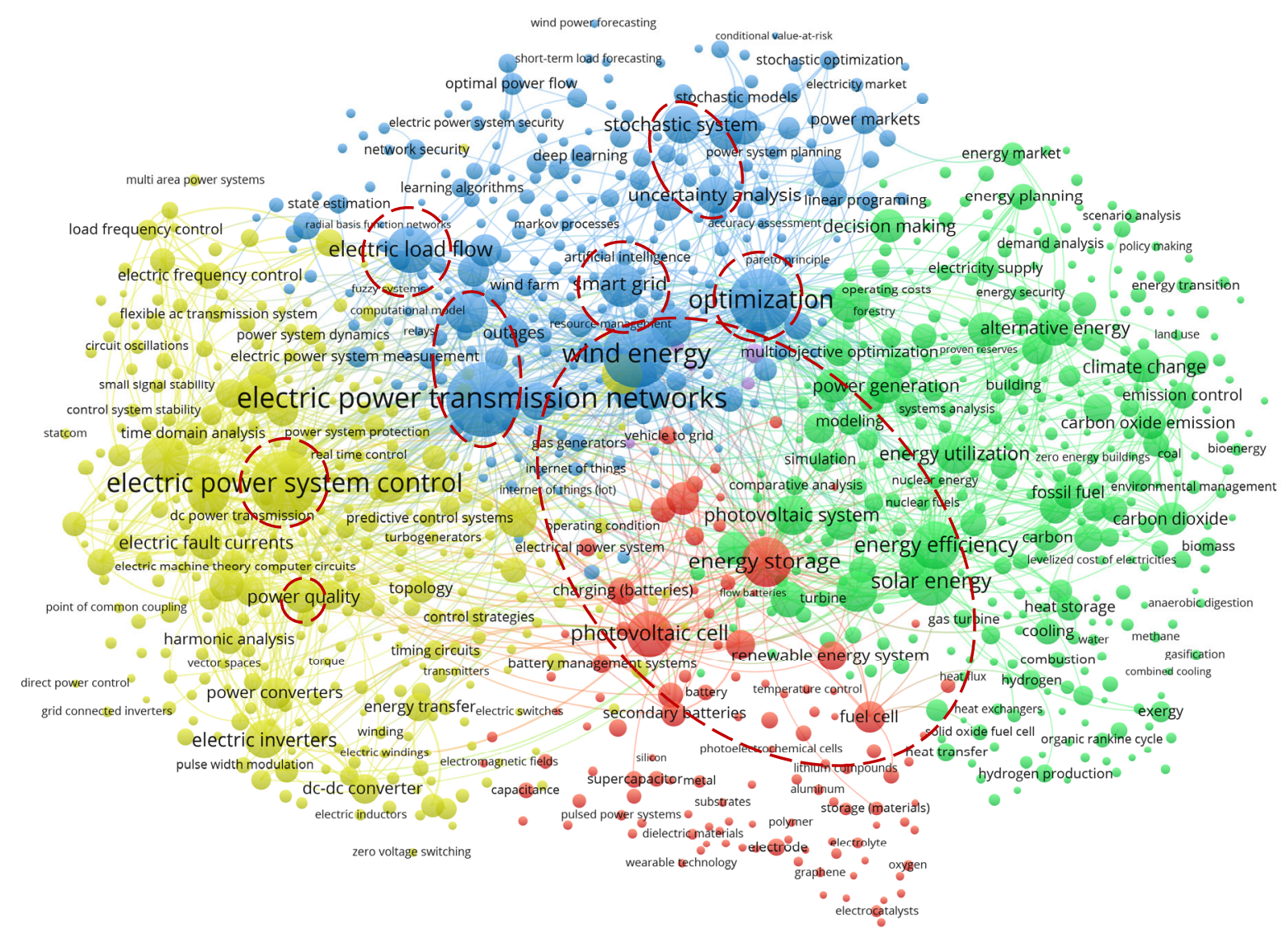

Fig. 8. Frontier of key research topics on energy systems for 2016-2020. 


\section{CONCLUSIONS}

This work presents an overview of energy systems research for the last 50 years through an exhaustive bibliometric analysis of scientific literature including more than 100,000 articles and reviews from the Scopus database. The science mapping approach is used as the main bibliometric method with further visual analysis using the co-citation technique and co-occurrences of keywords. This analysis was conducted using the VOSviewer software.

In opposite to the other bibliometric studies in energy this analysis mainly focuses on the transformation of the conceptual structure of the "energy systems/power systems" theme over a long period. Thus, the general topic hotspots and development trends in the research of energy systems were evaluated and visualized. It should be noted since the semantic meaning of basic terms the study concerns mainly electric power systems, but not energy systems in general. Energy systems related to heat supply and different kinds of perspective fuel supply (natural gas, hydrogen, methanol, etc.) were poorly considered in the study.

The study represents dynamics of most common topics of the knowledge domain, but more deep semantic structures and their interrelations have remained outside of the consideration yet. The quantification and classification of the multidisciplinary and complex field of energy systems are not simple. Future work implies the use of predesigned hierarchical ontology to overcome the existing gaps and to build an adaptive semantic model of developing the knowledge domain of energy systems.

The results of the study were presented and discussed at the conference "Energy-21: Sustainable Development \& Smart Management", September 7-11, 2020, Irkutsk, Russia.

\section{ACKNOWLEDGMENTS}

The research is funded by the Russian Foundation for Basic Research (project No. 20-07-00994).

\section{REFERENCES}

[1] Energy Systems as Objects of Hierarchical Modeling Energy Systems Research, Vol. 2, No. 4, 2019. http://dx.doi.org/10.25729/esr.2019.04.0001

[2] Balakrishnan, D., Haney, A. B., \& Meuer, J. (2016). What a MES(s)! A bibliometric analysis of the evolution of research on multi-energy systems. Electrical Engineering, 98(4), 369-374. https://doi.org/10.1007/s00202-016-0427$\underline{9}$

[3] Wang, L., Wei, Y. M., \& Brown, M. A. (2017). Global transition to low-carbon electricity: A bibliometric analysis. Applied Energy, 205(August), 57-68. https://doi.org/10.1016/j.apenergy.2017.07.107

[4] Gough, M., Santos, S. F., Javadi, M., Castro, R., \& Catalão, J. P. S. (2020). Prosumer flexibility: A comprehensive state-of-the-art review and scientometric analysis.
Energies, 13(11),

$1-32$.

https://doi.org/10.3390/en13112710

[5] Olawumi, T. O., \& Chan, D. W. M. A scientometric review of global research on sustainability and sustainable development. Journal of Cleaner Production, 183, 2018. Pp. 231-250. https://doi.org/10.1016/J.JCLEPRO.2018.02.162

[6] Van Eck, N. J., Waltman, L. Software survey: VOSviewer, a computer program for bibliometric mapping. Scientometrics, 84(2), 2010. 523-538.

https://doi.org/10.1007/s11192-009-0146-3

[7] Waltman, L., van Eck, N. J., \& Noyons, E. C. M. (2010). A unified approach to mapping and clustering of bibliometric networks. Journal of Informetrics, 4(4), 629-635. https://doi.org/10.1016/j.joi.2010.07.002

[8] Cui, Y., Xu, D., Liu, Z., \& Ross, D. (2020). Global Research and Trends in Renewable Energy: Ocean Waves, Tidal Energy and Offshore Wind. Journal of Coastal Research, 95(sp1), 1485-1489. https://doi.org/10.2112/SI95-286.1

[9] Aleixandre-Tudó, J. L., Castelló-Cogollos, L., Aleixandre, J. L., \& Aleixandre-Benavent, R. (2019). Renewable energies: Worldwide trends in research, funding and international collaboration. Renewable Energy, 139, 268278. https://doi.org/10.1016/j.renene.2019.02.079

[10] Perea-Moreno, M.-A., Samerón-Manzano, E., \& PereaMoreno, A.-J. (2019). Biomass as renewable energy: Worldwide research trends. Sustainability (Switzerland), 11(3). https://doi.org/10.3390/su11030863

[11] Obileke, K., Onyeaka, H., Omoregbe, O., Makaka, G., Nwokolo, N., \& Mukumba, P. (2020). Bioenergy from biowaste: a bibliometric analysis of the trend in scientific research from 1998-2018. Biomass Conversion and Biorefinery. https://doi.org/10.1007/s13399-020-00832-9

[12] Romo-Fernández, L. M., Guerrero-Bote, V. P., \& MoyaAnegón, F. (2013). Co-word based thematic analysis of renewable energy (1990-2010). Scientometrics, 97(3), 743-765. https://doi.org/10.1007/s11192-013-1009-5

[13] Gaviria-Marin, M., Merigó, J. M., \& Baier-Fuentes, H. (2018). Knowledge management: A global examination based on bibliometric analysis. Technological Forecasting and Social Change, 140(May 2018), 194-220. https://doi.org/10.1016/j.techfore.2018.07.006

[14] Rizzi, F., van Eck, N. J., \& Frey, M. (2014). The production of scientific knowledge on renewable energies: Worldwide trends, dynamics and challenges and implications for management. Renewable Energy, 62, 657-671. https://doi.org/10.1016/j.renene.2013.08.030

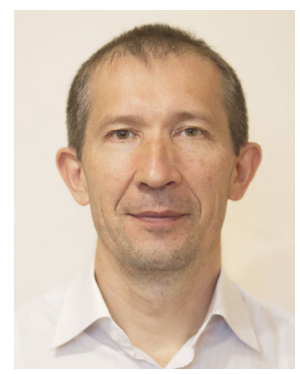

Alexey V. Mikheev graduated from the Faculty of Mathematics of the Irkutsk State University. He has Dr. of Eng. degree in technical sciences. $\mathrm{He}$ is a specialist in the field of mathematical modeling of thermal power equipment, technological forecasting, optical measurement, and flow visualization. 